\title{
RACISMO ESTRUTURAL E A POLÍTICA DE COTAS NAS UNIVERSIDADES FEDERAIS*
}

Michely Mezadri

\section{INTRODUÇÃO}

O presente estudo é fruto do acúmulo teórico desenvolvido com a dissertação de mestrado, ${ }^{1}$ que trata do trabalho da(o) assistente social na implementação das cotas sociais nas universidades federais do estado do Rio de Janeiro. Neste capítulo, apresentamos o conteúdo elaborado acerca da política de cotas para as universidades federais brasileiras a partir da promulgação da Lei $n^{\circ}$ 12.711/2012, compreendendo-a no contexto de uma política de ação afirmativa.

Pensar a política de cotas para as universidades federais brasileiras requer a inserção desta num contexto mais amplo, exigindo a compreensão das particularidades das nossas universidades e, por sua vez, da nossa formação social enquanto nação capitalista que se insere de forma dependente no capitalismo mundializado, determinação que expressa à necessidade de lutar por ações afirmativas.

Desta feita, distribuímos o capítulo em duas partes, um breve debate em torno da formação social brasileira, a partir das elaborações do intelectual militante Florestan Fernandes, com destaque para o racismo enquanto estrutural dessa formação para, num segundo momento, tratar da implementação da política de cotas nas universidades federais brasileiras com a promulgação da lei federal 12.711/2012.

*DOI - 10.29388/978-65-86678-36-9-0-f.265-282

${ }^{1}$ Dissertação de mestrado defendida em julho de 2020 com o título "O trabalho da/o Assistente Social na implementação da Política de Cotas Sociais nas Universidades Federais do Estado do Rio de Janeiro, sob orientação da Prof. ${ }^{a}$ Dr. ${ }^{a}$ Katia Regina de Souza Lima do Programa de PósGraduação em Serviço Social e Desenvolvimento Regional da Universidade Federal Fluminense UFF. 


\section{RACISMO ESTRUTURAL E A FORMAÇÃO SOCIAL BRASILEIRA}

O Brasil, assim como outras nações da América Latina, se insere no capitalismo mundializado de forma dependente das nações economicamente centrais. As nações de capitalismo dependente vivenciam a "condição colonial permanente" sofrendo alterações ao longo do tempo e até se redefinindo, sem jamais romper com a posição heteronômica. As estruturas econômicas, socioculturais e políticas internas são capazes de se incorporar ao capitalismo, sem romper com a condição de dependência, não promovendo assim o desenvolvimento autônomo da nação (FERNANDES, 2008).

A imposição dessa condição de dependência é externa (nações desenvolvidas), mas conta internamente, com o consentimento da burguesia local. Para o autor, as classes sociais sofrem aqui certo esvaziamento de suas funções sociais, mas adquirem a competência de se tornar um agente invisível da continuidade do subdesenvolvimento. A combinação do arcaico e do moderno - arcaico mantendo a dependência diante do capital externo e o moderno cumprindo o papel de ocultar essa relação - garante que o crescimento econômico não conduza a autonomia.

As classes sociais no capitalismo dependente sofrem modificações, adquirindo funções com destaque para o aproveitamento de oportunidades pelas classes privilegiadas que buscam concentrar para si "[...] uma renda, um prestígio e um poder já exageradamente concentrados" (FERNANDES, 2008, p. 75, grifo do autor). Estas buscam, a todo custo, preservar o seu poder, tomando-o como se o fosse sagrado, apresentando um verdadeiro pavor de realizar o rateio social do excedente econômico, até as transformações dentro da ordem capitalista são indigestas a burguesia local.

Insta destacar que Florestan Fernandes desenvolveu amplamente os estudos acerca do papel desempenhado pelas classes sociais no capitalismo dependente, entretanto, destacamos apenas as funções das classes privilegiadas, afinal são elas que conduzem e formatam as ações do Estado - não sem resistência - mas no capitalismo dependente evidencia-se que as classes dominantes apresentam um verdadeiro horror de fazer o rateio social e ver seu super privilegiamento ameaçado, tendo dificuldades de conduzir até as ações próprias da racionalidade capitalista. Assim estas, via Estado, conduzem a manutenção do capitalismo dependente e do subdesenvolvimento em níveis cada vez mais complexos, o que incide nas políticas públicas, como por exemplo, na política de educação, como apontaremos mais adiante. 
O racismo é uma importante marca do capitalismo dependente brasileiro. Os povos vindos do continente africano chegaram ao Brasil, durante o período colonial, para aqui serem escravizados, processo este que somente foi legalmente encerrado em 1888, no bloco das últimas nações do mundo a fazê-lo. Evidencia-se que antes mesmo do processo de abolição legal da escravidão o distintivo raça já era um fator de diferenciação entre os grupos que aqui habitavam, os índios e pretos tinham sua humanidade questionada, o que para Ortegal (2018) gerava uma espécie de “isenção moral” para a escravização e até extermínio desse grupo.

Considerando a natureza da relação estabelecida, não é possível pensar que apenas a extinção legal da escravidão alteraria automaticamente esta relação. Para Fernandes (2017) as elites brancas conduziram uma revolução social, sem que essa atingisse as relações raciais, não alterando, assim, a condição dos negros. Desta feita, a diferenciação entre brancos e pretos vai se perpetuando sociologicamente e o racismo sofrendo uma espécie de aperfeiçoamento, fazendo com que o componente raça e, por consequência, o racismo apresente-se como estrutural da nossa formação capitalista tardia, periférica e dependente.

O racismo aqui praticado é marcado pela manifestação tipicamente fenotípica atrelada a cor da pele e operado no cotidiano. Temos assim um racismo de marca, cotidiano e que oculta à face daqueles que o praticam, para FERNANDES (2007, p. 42, grifo da autora) há no Brasil uma espécie de racismo particular "[...] um preconceito de não ter preconceito" tornando-o algo moralmente condenável para quem pratica e ultrajante a quem sofre.

O debate em torno do racismo, na perspectiva estrutural é apresentado por Almeida (2019) a partir da ideia deste enquanto um processo histórico e político. O racismo é considerado assim, um elemento constitutivo dos Estados Modernos, sendo alimentado e se alimentando das estruturas estatais. $\mathrm{O}$ autor apresenta uma definição de Estado para além das noções de "bem comum", demarcando-o como uma forma específica de exercício de poder e de dominação.

Nessa perspectiva, compreendemos que o racismo é estrutural no capitalismo dependente brasileiro e opera mecanismos de exclusão bem particulares a nossa realidade, que pode ser verificado nas mais diversas esferas da vida do povo preto, desde as manifestações mais escancaradas no cotidiano à perversidade das ações de racismo institucionalizadas, daí a necessidade de lutar por ações afirmativas que busquem corrigir as desigualdades perpetradas através das muitas faces que operam o racismo em nossa sociedade. 
Antes de adentrar no debate em torno das ações afirmativas, trataremos de algumas particularidades das universidades federais brasileiras para compreendermos os contornos dramáticos que levam a necessidade de lutar por ações afirmativas no âmbito da educação, em especial da política de cotas.

Conforme aponta Fernandes (2008) o capitalismo dependente é mais que uma realidade econômica, ele é uma complexa realidade sociocultural, interferindo na organização econômica, política e social das nações. A educação superior no Brasil somente é desenvolvida para atender a demanda das elites, no sentido de preparação destas para a inserção nas fases mais avançadas do modo de produção capitalista.

O ensino superior é transplantado aqui com base no modelo europeu, porém, sofrendo alguns níveis de empobrecimento funcional e estrutural, quais sejam: não implantação dos modelos em sua integralidade; ocorre o esvaziamento de suas funções no sentido de limitar o desenvolvimento cultural e, por fim, o modelo de escola superior objetivava apenas formar um letrado com formação técnica para atender as demandas burocráticas e de profissionais liberais (FERNANDES, 1975).

As instituições de ensino superior sofrem um processo que Fernandes (1975) identificou como "senilização institucional precoce", uma espécie de novo que já nasce velho, devido ao atraso que os modelos escolhidos para transplantação representavam, desenvolvendo assim o que o autor denominou de "padrão brasileiro de escola superior". Forjou-se, assim, uma escola superior brasileira para atender as elites culturais locais, com horizontes educacionais bem limitados, reproduzindo conhecimento importado do exterior e formando profissionais liberais.

Nessa perspectiva, identifica-se que a escola superior brasileira reflete características comuns a sociedade na qual foi gestada, ou seja, assim como a formação social, as escolas superiores e, mais tarde as universidades, se caracterizam como instituições hierarquizadas, rígidas e exclusivistas. Estas espelham outros três aspectos particulares do tipo de desenvolvimento, quais sejam: transformar o saber numa espécie de símbolo de distanciamento ou diferenciação social; converter a capacidade de educar em poder, e transformar o professor em um meio de controle sob as novas gerações. Com estas características, as instituições acabam por se fechar em si mesmas, cumprindo de forma rigorosa apenas suas funções essenciais, qual sejam, formar um determinado tipo de letrado e transmitir, de forma dogmática, o conhecimento (FERNANDES, 1975). 
No desenvolvimento da educação superior brasileira ocorre a passagem do modelo transplantado da escola superior isolada para o desenvolvimento das universidades, entretanto, essa alteração não propiciou um processo interno de diferenciação e de autocrescimento que servisse de base para o surgimento das universidades. Ocorre na verdade uma "[...] uma mera aglomeração de escolas superiores e um recurso para preservá-las, fortalecê-las e difundi-las, com suas magras virtudes e com seus incontáveis defeitos" (FERNANDES, 1975, p. 56).

As universidades brasileiras foram criadas com objetivo de atender as demandas das elites locais, com características comuns a sociedade na qual foram gestadas. Considerando as características destacadas, em uma sociedade estruturalmente racista, uma burguesia local que apresenta verdadeiro horror de realizar o rateio social do excedente econômico e que transformou o saber num símbolo de distanciamento social, é previsível que amplas parcelas da população, em especial a população negra, fosse historicamente alijada do acesso à educação, em especial, da Universidade.

Neste contexto insta destacar alguns dados que, mesmo no presente século, reafirmam o alijamento histórico de amplas parcelas da população à educação. Dados do relatório "Retratos das Desigualdades de Gênero e Raça" referentes ao acesso à política de educação revelam uma dura realidade. Dos jovens considerados analfabetos, com 15 anos ou mais, em 2015, aproximadamente $72 \%$ são negros contra $28 \%$ de brancos. No mesmo ano, das pessoas com 25 anos ou mais com menos de 1 ano de escolarização, verifica-se que apenas 7,4\% eram brancos e 14,4 \% negros (INEP, 2017).

Ao analisar os dados da educação superior a discrepância se evidencia de forma mais assustadora. A taxa de escolarização líquida ${ }^{2}$ do ensino superior no Brasil, para o ano de 2015 foi de 17,8 \%. O mesmo dado estratificado por raça revela que $25 \%$ são brancos, já o percentual de pretos é de $12,5 \%$, para este dado considera-se estudantes matriculados na graduação, mestrado e doutorado (INEP, 2017).

Mesmo 127 anos após o fim legal da escravidão, o retrato da marginalização e da estigmatização do povo preto é reafirmando historicamente pelos mecanismos de barragem em diversas instâncias. Como ilustram os dados, as marcas do racismo estrutural brasileiro perpassam as diversas esferas da vida, pois como lembra Fernandes (2017, p. 100) "[...] a desigualdade racial é uma das desigualdades estruturais da sociedade brasileira”. A luta para corrigir as desi-

\footnotetext{
${ }^{2}$ A taxa de escolarização líquida - equivale a proporção da população que está matriculada no nível de ensino considerado adequado para a sua faixa etária.
} 
gualdades que o racismo tem perpetuado ao longo dos anos tem como pauta importante as ações afirmativas.

Para Guasti (2016) podemos considerar três aspectos fundantes das ações afirmativas, quais sejam: combate à discriminação, busca por corrigir os efeitos desta e a tentativa de efetivação da igualdade substantiva, assim definida:

As ações afirmativas representam um conjunto de ações públicas que visam o rompimento de desigualdades históricas ou sociais no acesso ao efetivo exercício de direitos, bens e serviços considerados essenciais para uma vida digna. Desigualdades essas que não conseguem ser rompidas com os mecanismos tradicionais de inclusão social, como a expansão de mercado de trabalho ou o acesso universal à educação (ROZAS, 2009, p. 20).

Em uma nação marcada estruturalmente pelo racismo, que apresenta dados alarmantes de desigualdade social com recorte racial, a luta por ações afirmativas que visem ao menos minorar as desigualdades jamais podem assumir contornos de vitimismo. A luta por ações afirmativas é, portanto, legítima e necessária. Desta feita, esta luta no Brasil tem um largo caminho percorrido que é fruto da luta dos movimentos de mulheres, pessoas com deficiência e movimento negro.

Considerando o debate em torno das cotas nas universidades federais, destacaremos as primeiras iniciativas de ações afirmativas em torno da reserva de vagas na educação que identificamos. Como o debate aqui se concentra no âmbito da política de educação apresentamos algumas iniciativas nesse plano, evidenciando que as ações afirmativas somente alcançam a educação nas últimas décadas. A guisa de exemplo temos a Lei $n^{\circ} 5.465 / 1968$ e o projeto de Lei $1.332 / 1983$.

A então conhecida Lei do Boi, Lei no 5.465 de 03 de julho de 1968, é assim conhecida por reservar 50\% das vagas nas escolas de ensino médio agrícola e superior de agricultura e veterinária para os filhos de proprietários de terras. A primeira iniciativa em prol da reserva de vagas para ingresso na escola/ universidade destinou-se a reservar vagas para os filhos dos latifundiários brasileiros, sendo revogada apenas em 1985 (GUASTI, 2016). Acerca desta lei, Santos (2016) explica que foi uma solicitação dos "ruralistas" e que não foi pauta do povo negro e nem os beneficiou.

O projeto de Lei $n^{\circ} 1.332 / 1983$ de autoria do então deputado Abdias do Nascimento propôs a reserva de 40\% das vagas do vestibular do Instituto Rio Branco do Ministério das Relações Exteriores para Negros, sendo subdivi- 
dida em $20 \%$ para mulheres e os outros $20 \%$ para homens, o projeto definiu a medida de reserva de vaga enquanto uma medida compensatória que visava a isonomia do negro, entretanto o projeto foi arquivado em 1989 (BRASIL, 1983).

Santos (2016) apresenta ainda como um marco importante para a construção das ações afirmativas a realização, em 1995, da Macha Zumbi dos Palmares contra o racismo e pela vida, que resultou na elaboração de um documento propondo uma série de medidas a serem adotadas pelo Estado para a população negra em diversos eixos. Esse documento foi entregue ao presidente Fernando Henrique Cardoso que criou um Grupo de Trabalho para pensar a pauta proposta.

Insta destacar que, é no mínimo curioso evidenciar que uma das primeiras modalidades de reserva de vagas na educação, realmente efetivada, seja justamente para beneficiar aos filhos dos latifundiários brasileiros. Não obstante, o projeto de lei que visava garantir aos negros um percentual de reserva de vagas no vestibular do instituto Rio Branco, foi arquivado. O projeto de lei que dará origem a lei federal de cotas foi proposto apenas em 1999 e será melhor detalhado a seguir.

\section{POLÍTICA DE COTAS NAS UNIVERSIDADES FEDERAIS}

O Brasil é um país que se insere no capitalismo mundial de forma dependente, tendo o racismo como estrutural e que reflete as particularidades de sua formação na constituição da educação superior, tornando a educação em símbolo de diferenciação e o saber como fonte de poder, conforme explica Florestan Fernandes em suas obras.

É exatamente graças a essas determinações que as ações afirmativas se fazem tão necessárias e fundamentais na luta contra as desigualdades sociais e raciais. No âmbito da educação superior as ações afirmativas apresentam, entre outras importantes pautas, a luta em torno da política de cotas para as universidades públicas. Não obstante as mobilizações e lutas, somente em 2012 é promulgada a lei Federal de Cotas após anos de tramitação do projeto original de lei.

A deputada do PFL/AM Nice Leão, em 1999, apresenta o projeto de lei - PL n 73 que versa acerca da reserva de vagas para as universidades federais em todo território brasileiro. Originalmente o projeto de lei previa a reserva de vagas nas universidades federais para estudantes que concluíram o ensino 
médico em escolas públicas. Ao projeto original foram apensados outros projetos de leis e também algumas emendas, com destaque para a inclusão da categoria "Pardo" para a ação afirmativa que passa a ser para "Pretos, Pardos e Indígenas" - PPI. Outra alteração importante é a ampliação da reserva de vagas para todas as instituições de ensino federais (Escolas técnicas e institutos federais).

Em 2004, o projeto de lei recebeu o apensamento do 3.627/2004, pois ambos tratavam da reserva de vagas. Este PL versa sobre a reserva de vagas especiais para ingresso na educação superior definindo o percentual de $50 \%$ com reserva especial para Negros e Indígenas, colocando o Ministério da Educação, a Secretaria Especial de Políticas de Promoção da Igualdade Racial da Presidência da República como responsáveis pelo acompanhamento e avaliação da reserva de vagas, ouvindo ainda a FUNAI - Fundação Nacional do Índio.

Conforme consta no site da Câmera dos deputados, o deputado Miro Teixeira do PDT/SP solicitou a votação do PL 73/1999 em regime de urgência no ano de 2006, o que não ocorreu. O pedido de urgência para votação ainda foi solicitado por mais dois deputados em 2007 , sem sucesso. O projeto foi apensado a outros projetos de lei e chegou a entrar em votação em 2008, entretanto, somente é aprovado em 2012, transformando-se na Lei Ordinária ${ }^{\circ}$ 12.711 sancionada em 29 de agosto de 2012.

A lei aprovada estabeleceu que cada universidade federal deveria reservar, no mínimo, $50 \%$ das vagas para estudantes que cursaram integralmente o ensino médio nas escolas da rede pública de ensino. Estas vagas ainda são subdivididas em cotas sociais, - destinando 50\% desta para estudantes que comprovem renda familiar de até 1,5 salário-mínimo; cotas raciais, destinadas aos autodeclarados pretos, pardos e indígenas - PPI de acordo com o percentual dessa população segundo o IBGE; e, ainda, cotas para pessoas com deficiência. O projeto de lei recebeu um único veto, justificado a impossibilidade de seleção dos alunos via coeficiente de rendimento (CR) devido a não padronização da atribuição de notas pelas diversas instituições de ensino do país (BRASIL, 2012).

Ficou definido em lei um prazo de quatro anos para que todas as universidades se adequassem integralmente a lei, facultando a cada ano a adoção de $25 \%$ das cotas. Outra previsão ainda é que em 2022, dez anos após a promulgação da lei, deverá ocorrer uma revisão do programa especial de ingresso nas instituições (BRASIL, 2012).

Segundo previsão legal, o critério inicial para se candidatar em qualquer uma das modalidades para as universidades é ter cursado o ensino médio em 
instituições da rede pública de ensino. A lei prevê ainda que do total de vagas disponibilizadas para cada curso, sejam reservados no mínimo $50 \%$ para as ações afirmativas distribuídas nas seguintes modalidades: a) candidatos com renda familiar bruta per capita igual ou inferior a 1,5 salário-mínimo que tenham cursado integralmente o ensino médio em escolas públicas; b) candidatos autodeclarados pretos, pardos ou indígenas, com renda familiar bruta per capita igual ou inferior a 1,5 salário-mínimo e que tenham cursado integralmente o ensino médio em escolas públicas; c) candidatos com deficiência que tenham renda familiar bruta per capita igual ou inferior a 1,5 salário-mínimo e que tenham cursado integralmente o ensino médio em escolas públicas; d) candidatos com deficiência autodeclarados pretos, pardos ou indígenas, que tenham renda familiar bruta per capita igual ou inferior a 1,5 salário-mínimo e que tenham cursado integralmente o ensino médio em escolas públicas; e) Candidatos que, independentemente da renda, tenham cursado integralmente o ensino médio em escolas públicas; f) Candidatos autodeclarados pretos, pardos ou indígenas que, independentemente da renda, tenham cursado integralmente o ensino médio em escolas públicas; g) candidatos com deficiência que, independentemente da renda, tenham cursado integralmente o ensino médio em escolas públicas; e, h) Candidatos com deficiência autodeclarados pretos, pardos ou indígenas que, independentemente da renda, tenham cursado integralmente o ensino médio em escolas públicas.

Conforme podemos observar as cotas estabelecem como critério principal a origem escolar, ou seja, oriundos das escolas públicas, definindo como subcritérios a questão racial, situação socioeconômica ou cotas sociais, e a condição de pessoa com deficiência incorporada pela lei 13.409 em 2016.

O modelo de reserva de vagas adotado por meio desta lei privilegia a reserva de vagas para estudantes oriundos de escolas públicas, deixando em segundo plano o recorte racial, não obstante todas as manifestações e mobilizações ${ }^{3}$ em prol das cotas, serem uma reivindicação histórica do movimento negro. Insta destacar que durante todo este tempo algumas universidades, por meio da autonomia universitária, implementaram seu próprio sistema de reserva de vagas, a UERJ (em 2001) e a UnB (em 2003) foram pioneiras na implemen-

\footnotetext{
${ }^{3}$ Autores como Santos (2016) e Coutinho (2018), entre outros, destacam a trajetória histórica do Movimento Negro brasileiro em torno da implementação das ações afirmativas e a luta por educação, apresentando diversas reivindicações e ações adotadas pelo conjunto desses movimentos, com destaque para a Macha Zumbi dos Palmares realizada em 1995, as ações do Movimento Negro Unificado - MNU como a luta pelo ensino de História da África e do Negro no Brasil nos currículos escolares, entre outras tantas pautas e lutas do movimento.
} 
tação da reserva de vagas, como estamos tratando das universidades federais, passamos a apresentar o caso da UnB.

Por meio de sua autonomia universitária, a Universidade de Brasília UnB, aprovou em junho de 2003 a resolução no 38/2003 do Conselho de Ensino Pesquisa e Extensão - CEPE que institui o "Plano de metas para integração social, étnica e racial da universidade de Brasília". O referido documento foi elaborado pelos professores José Jorge de Carvalho e Rita Laura Segato, fruto de um amplo debate na comunidade acadêmica iniciado em 1999 e prevê, entre outras ações, a destinação de $20 \%$ das vagas do vestibular, por curso, para estudantes negros (UNB, 2003).

O processo de construção das cotas na $\mathrm{UnB}$ reconheceu a demanda por uma política de cotas para a universidade, enquanto uma questão racial, para além do atravessamento das questões econômicas que envolvem a situação da população negra no Brasil. Assim, a UnB torna-se pioneira na implementação de cotas raciais. O amplo leque de argumentação dos autores da proposta apresenta e refuta os mais comuns argumentos contrários a cotas, tais como: necessidade de investir na educação básica, nos cursinhos populares para negros, a ideia de implementar cotas sociais sob o argumento que já contemplariam os negros, entre outros (CARVALHO; SEGATO, 2002).

Insta destacar a argumentação dos autores que defendem que nem as cotas sociais (recorte de renda), nem as cotas para estudantes de escola pública poderiam suprimir a necessidade de cotas raciais considerando a especificidade do problema racial brasileiro. Argumentam que as cotas sociais podem sim atingir, indiretamente, os indivíduos negros, entretanto os dados ${ }^{4}$ apresentados na proposta revelam que os pobres brancos já contam com maior vantagem de escolarização e afirmam: "[...] ser negro no Brasil é ter menos acesso à educação" (CARVALHO; SEGATO, 2002, p. 10). Assim, defendem que as cotas com recorte social, independentemente da cor, acabam por reforçar a desigualdade, já marcante entre negros e brancos que formam a população pobre deste país. A argumentação do documento segue afirmando, também com base nos dados, que a adoção de cotas para estudantes oriundos da escola pública não atenderia

\footnotetext{
${ }^{4}$ Os autores apresentam diversos dados que refletem a desigualdade de acesso à educação que decorrem da discriminação de racial, como a pesquisa do IPEA com crianças de 11 a 14 anos que pertencem aos $25 \%$ mais pobres no país. Verifica-se que os meninos brancos deste grupo, $44 \%$ estão cursando o ensino médio, entre os meninos negros, o percentual cai para $27 \%$. Outro dado apontado no estudo explica que apenas $8,3 \%$ dos brancos com mais de 15 anos são analfabetos enquanto entre os negros na mesma idade o percentual é de 20\% (CARVALHO; SEGATO, 2002).
} 
de pronto aos estudantes negros, pois, a mesma diferenciação entre os pobres brancos e pobres negros se reflete nas escolas públicas.

É fundamental destacar que a experiência da UnB foi debatida nacionalmente e, como datada de 2004, poderia sim ter influenciado na construção da lei federal que regulamentou a reserva de vagas nas universidades e institutos federais brasileiros, entretanto, verificamos que o legislador optou majoritariamente pela adoção da reserva de vagas para estudantes oriundos de escolas públicas, colocando a questão racial em segundo plano.

Considerando o exposto, defendemos que a luta por acesso à educação e de maneira geral, por ações afirmativas, conforme destaca Santos (2016, p. 82): “[...] estabelece uma relação direta entre as demandas do povo negro e as desigualdades sociais e raciais que eles sofrem no País, cujo mito da democracia racial tente a ofuscar e invisibilizar as injustiças", nos cabe a seguinte questão: Porque o modelo adotado pelo governo brasileiro por meio da lei federal sancionada em 2012, privilegia a reserva de vagas para estudantes egressos de escolas públicas, colocando a pauta dos negros e índios em segundo plano?

Acreditamos que talvez uma resposta para essa questão perpasse num misto de racismo institucional ${ }^{5}$ que impregna a sociedade brasileira e as históricas manobras das classes dominantes em relação às conquistas da classe dominadas, como bem exemplifica Mattos (2007):

[...] conhecedores dos processos históricos complexos, sabemos que conquistas parciais das classes subalternas são muitas vezes compensadas por manobras das classes dominantes que anulam seu raio de ação e limitam sobremaneira sua efetividade. Pensemos, por exemplo, em como as conquistas democráticas da classe trabalhadora e seus aliados, desde o século XIX (como o sufrágio universal), foram tendo seus efeitos minorados pelas manobras dos dominantes (instituindo fórmulas bicamerais de legislativo; colégios eleitorais, regimes bipartidários e mais recentemente - "marketing eleitoral, entre outros), de forma a evitar um real poder popular através do voto" (MATTOS, 2007, p. 182).

A escolha por apresentar o exemplo de reserva de vagas implementada pela UnB fundamenta-se na crença de que o modelo de reserva de vagas sancionado pela lei 12.711/2012 nega a histórica reivindicação da população negra

\footnotetext{
${ }^{5}$ Segundo Ortegal (2018) o racismo institucional relaciona-se a questões materiais de acesso ao poder e que esta dimensão do racismo não se materializa nas ações de um único indivíduo, mas é verificada de forma difusa nas dinâmicas institucionais, no modo de operar, na dificuldade de acesso a informações, entre tantas outras formatações.
} 
em prol das ações afirmativas, em especial, do acesso à educação e educação superior no Brasil, conforme destaca:

[...] há uma estreita relação das Ações Afirmativas tanto com as trajetórias de vidas dos afro-brasileiros relacionadas com a História do Brasil marcadamente desigual social e racialmente, quanto pelas lutas desses grupos que sempre solicitaram e gritaram, dentre muitas coisas, em prol do direito à educação. A história das Ações Afirmativas, em nosso país, já tem um caminho largo que foi percorrido não apenas pelo grupo negro, mas, também, por mulheres, deficientes, idosos etc. (SANTOS, 2016, p. 82).

Não obstante todo o debate realizado na sociedade e a iniciativa da universidade relatada acima, o governo federal aprova, em 2012, um modelo de reserva de vagas que secundariza a demanda racial, colocando-a sob o crivo de dois outros critérios: origem escolar e renda. Após a promulgação da referida lei, a UnB em 2013, cria uma comissão para avaliar a política de cotas implementada em 2004, esta elabora um documento com uma rica análise acerca do modelo de cotas aprovado pela lei federal, fazendo críticas à lei em comparação com o modelo já consolidado na universidade, entre os pontos apresentados pela comissão, destaco:

Afinal, com um teto de 50\% para cotas de escola pública já não fará sentido chamar os outros 50\% de concorrência geral, ou universal, pois eles se converterão, na prática, em cotas para escola privada. Nesse contexto geral, as desvantagens numéricas entre brancos e negros serão contundentes. Senão, veja.

Se somar os $25 \%$ reservados pelas cotas para os brancos de escola pública aos 50\% de vagas ditas gerais (que serão de fato ocupadas pelos brancos de escolas particulares), as vagas ofertadas pelas instituições federais tenderão a ser assim distribuídas:

- brancos: 25\% de escolas públicas $+50 \%$ de escolas privadas $=75 \%$ das vagas

- negros: $25 \%$ das vagas

Mais desigual ainda será a relação entre os brancos de classe média e os negros de classe média no que tange à conquista de vagas.

- brancos de classe média: $50 \%+12,5 \%=62,5 \%$ do total de vagas:

- negros de classe média: $12,5 \%$ do total de vagas

A desigualdade entre negros e brancos crescerá ainda mais se pensarmos nas proporções dos estudantes de escolas públicas e os de escolas privadas, que é de $89 \%$ para $11 \%$. Ou seja;

$89 \%$ dos estudantes de ensino médio público ficarão com $50 \%$ das vagas $11 \%$ dos estudantes de ensino médio privado ficarão com $50 \%$ das vagas 
Em vista desta diferença, os estudantes do ensino privado (em sua maioria brancos) terão um coeficiente de representação no ensino superior 8 vezes maior que dos estudantes do ensino público (onde estarão concentrados os negros).

O único espaço em que haverá equilíbrio será nos 25\% de cotas de baixa renda, que serão divididas em partes iguais:

- $12,5 \%$ para brancos de baixa renda

- 12,5\% para negros e indígenas de baixa renda (UNB, 2013, p. 38).

Desta feita, podemos concluir, em consonância com o apresentado no documento de UnB, que a lei ordinária $\mathrm{n}^{\circ} 12.711 / 2012$, analisada sob a perspectiva da inclusão étnico racial desta população nas universidades federais brasileiras representa um retrocesso frente aos modelos já implementados, como o caso da UnB, que a partir dessa lei terá de adequar seus sistemas ao modelo aprovado. Vale destacar ainda que, ao definir como critério maior a origem escolar dividindo exatamente a metade das vagas para escolas públicas automaticamente, a outra metade acaba destinando-se aos egressos de escolas particulares, sobretudo, nos cursos de maior concorrência ou "cursos de maior prestígio social" como Medicina, Direito e as Engenharias.

É importante destacar ainda, o julgamento no STF (Superior Tribunal Federal), que entendeu como constitucional as cotas raciais em abril de 2012, quatro meses antes da promulgação da lei 12.711/2012. O STF declarou constitucional a reserva de vagas para negros independentemente de critérios econômicos, por 10 votos favoráveis e 0 contra, inclusive, recomendando a adoção do modelo implementado na $\mathrm{UnB}^{6}$, que foi desconsiderado por ocasião da sanção da referida lei, reforçando o argumento em torno da enorme dificuldade do país em reconhecer o racismo estrutural existente, objeto de necessária intervenção estatal na reparação das desigualdades geradas por este.

A meu ver corroboram esse argumento, dois projetos de lei em tramitação atualmente no Congresso que versam sobre a política de cotas. O primeiro, é o projeto de lei n ${ }^{\circ} 1531 / 2019$ proposto pela deputada Professora Dayane Pimentel (PSL-BA), que deseja alterar a lei 12.711 para excluir com o subcritério racial da lei de cotas, pois, segundo a autora este critério - fere o art. $3^{\circ}$ da Constituição que tem como objetivo "[...] promover o bem de todos, sem preconceito de origem, raça, sexo, cor, idade e quaisquer outras formas de discriminação" (BRASIL, 1988, snp.) - ao contrariar a vedação constitucional de

\footnotetext{
${ }^{6}$ Vale ressaltar que atualmente a UNB, adotou o sistema de cotas conforme expresso na Lei $12.711 / 2012$, entretanto, reservou $5 \%$ das vagas para negros independente da comprovação de origem escolar e renda, garantindo assim uma reserva de mais de $50 \%$ do total de vagas, buscando corrigir as desigualdades entre brancos e pretos.
} 
"quaisquer formas de discriminação", assim os pretos, partos e indígenas não devem ser destinatários dessa política. Fato curioso é que tal projeto corrobora, sem justificativa, a necessidade de se manter a "discriminação positiva" para as cotas sociais (estudantes com renda de até 1,5 salário-mínimo) e também para pessoas com deficiência, pois segundo a autora, estes "[...] sim carecem de atenção especial" (BRASIL, 2019, snp).

O segundo é o projeto de lei $n^{\circ} 5303 / 2019$ apresentado em outubro pelo deputado Sr. Jaziel do PL/CE que foi apensado ao primeiro, pois tratam do mesmo tema. Este novo projeto prevê excluir as "cotas raciais", sob a justificativa de que esta modalidade impediria o ingresso nas universidades dos estudantes das cotas sociais, solicitando assim a exclusão do critério de raça no momento de avaliação da política de cotas previsto para 2022, conforme a lei 12.711/2012. O projeto de lei mantém a previsão das cotas sociais e cotas para pessoas com deficiência, argumentando que, com as cotas raciais, o público das universidades chegou a 39\% como se as cotas raciais impedissem as cotas sociais, revelando, além do racismo, um verdadeiro desconhecimento do funcionamento da política.

Os projetos de lei revelam e confirmam o racismo como estrutural da formação social brasileira, que ainda, na atualidade, opera as mais diversas formas de exclusão. Para combatê-lo é fundamental escancará-lo, uma vez a justificativa apresentada em ambos os projetos não escreve de forma explicita a real motivação para exclusão do critério raça da lei de cotas, o racismo se revela na argumentação para defender a manutenção dos critérios de renda e para pessoas com deficiência, revelando as incoerências. É fundamental reafirmar que o racismo não é decorrente do problema de classe, pois como afirma Fernandes (2017, p. 40) "Aqueles que conseguem varar as barreiras sociais, qualificando-se como técnicos ou como profissionais liberais, logo se defrontam com as barreias raciais".

\section{CONSIDERAÇÕES FINAIS}

No presente capítulo buscamos apresentar a análise da política de cotas implementada com a Lei Federal no 12.711/2012 numa perspectiva teórica que compreende a referida lei a partir das múltiplas determinações que compõem essa realidade. Partimos assim de uma breve apresentação da formação social brasileira compreendendo-a nos limites e consequências do capitalismo dependente cujo racismo se apresenta como estruturante. 
As universidades brasileiras se conformaram para atender as elites locais, alijando de seu acesso largas parcelas da população em especial, a população negra, como revelam os dados. Desta feita, as lutas por ações afirmativas que busquem garantir efetivamente o acesso e a permanência dessa parcela da população, são mais que necessárias no país e defendê-las, na atualidade, frente aos ataques torna-se urgente.

A análise da referida lei identifica que não obstante a ampla mobilização em torno das cotas raciais, o legislador optou por um modelo que privilegia a origem escolar como critério principal, secundarizando as cotas sociais e raciais, o que a nosso ver, expressa as características da nossa burguesia racista e elitista e que tem verdadeiro horror em promover o rateio social e ver ameada sua concentração de renda, prestígio social e poder, conforma aponta Fernandes (2008). Embora a Lei Federal de Cotas represente um marco importante na luta por acesso à educação e, por isso, torna-se fundamental defendê-la, o Estado ao incorporar essa pauta do movimento, buscou, por outros meios, esvaziá-la do seu significado político, o que se expressa em mais uma manifestação atual do racismo estrutural.

\section{REFERÊNCIAS}

ALMEIDA, S. L. de. Racismo Estrutural. São Paulo: Sueli Careniro/Polén, 2019.

BRASIL. Lei n 12.711 de 29 de agosto de 2012. Dispõe sobre o ingresso nas universidades federais e nas instituições federais de ensino técnico de nível médio e dá outras providências. Câmara dos Deputados, Brasília, DF, 29 ago. 2012. Disponível em: < https://www2.camara.leg.br/legin/fed/lei/2012/lei12711-29-agosto-2012-774113-norma-pl.html>. Acesso em: 06 ago. 2020.

Lei $\mathrm{n}^{\circ} \mathbf{5 . 4 6 5}$ de 03 de julho de 1968. Dispõe sobre o preenchimento de vagas nos estabelecimentos de ensino agrícola. Câmara dos Deputados, Brasília, DF, 03 jun. 1968. Disponível em: < https://www2.camara.leg.br/legin/ fed/lei/1960-1969/lei-5465-3-julho-1968-358564-publicacaooriginal-1-pl.html>. Acesso em: 25 abr. 2020.

Projeto de lei $\mathbf{n}^{\circ} \mathbf{1 3 3 2}$, de 14 de junho de 1983. Dispõe sobre a ação compensatória, visando a implementação do princípio da isonomia social do 
negro, em relação aos demais segmentos etnicos da população brasileira, conforme direito assegurado pelo artigo 153, parágrafo primeior, da constituição da república. Brasília, DF, 14 jun. 1983. Disponível em: < https://www.camara.leg.br/proposicoesWeb/fichadetramitacao?idProposicao=190742>. Acesso em: 20 ago. 2020.

Projeto de lei $\mathrm{n}^{\circ} \mathbf{1 5 3 1} \mathbf{2 0 1 9}$, de 19 de março de 2019. Altera os arts. $3^{\circ}, 5^{\circ}$ e $7^{\circ}$ da Lei $n^{\circ} 12.711$, de 29 de agosto de 2012, para retirar o mecanismo de subcotas raciais para ingresso nas instituições federais de ensino superior e de ensino técnico de nível médio. Brasília, DF, Câmara dos Deputados, 19 mar. 2019. Disponível em: < https://www.camara.leg.br/proposicoesWeb/fichadetramitacao?idProposicao=2194298 > . Acesso em: 20 ago. 2020.

Constituição da República Federativa do Brasil, 5 de outubro de 1988. Promulga a Constituição da República Federativa do Brasil. Brasília. DF. Planalto. 5 out. 1988. Disponível em: < http://www.planalto.gov.br/ ccivil 03/constituicao/constituicao.htm>. Acesso em: 15 ago. 2020.

CARVALHO, J. J. de.; SEGATO, R. L. Uma proposta de cotas para estudantes negros na universidade de Brasília. Brasília: UNB, 2002. Disponível em: $<$ https://www.noticias.unb.br/76-institucional/2319-aprovacao-das-cotasraciais-na-unb-completa-15-anos >. Acesso em: 03 out. 2019.

COUTINHO, A. L. Afirmação Política e Política Afirmativa: Cotas para negros na Universidade Federal do Espírito Santo. 2018. . Dissertação (Mestrado em Política Social) - Programa de Pós-Graduação em Política Social, Universidade Federal do Espírito Santo, Vitória/ ES. 2018.

FERNANDES, F. Universidade Brasileira: reforma ou revolução? São Paulo: Alfa-Omega, 1975.

O negro no mundo dos brancos. 2. ed. rev. São Paulo: Global, 2007.

Sociedade de Classes e subdesenvolvimento. São Paulo: Editora Global, 2008.

Significado do protesto negro. São Paulo: Expressão Popular, 2017. 
GUASTI, M. C. F. A. Representações Sociais: Sobre as ações afirmativas no ensino superior e sobre os estudantes cotistas da UFES. Curitiba: CRV, 2016.

INSTITUTO NACIONAL DE ESTUDOS E PESQUISAS EDUCACIONAIS ANÍSIO TEIXEIRA. Sinopse estatística da educação superior 2016. Brasília: INEP, 2017. Disponível em: < http://inep.gov.br/web/guest/sinopses-estatisticas-da-educacao-superior $>$. Acesso em: 09 ago. 2020.

MATTOS, M. B. Cotas, raça, classe e universalismo. Revista Outubro, n. 16, snp, $2^{\circ}$ Semestre, 2007.

ORTEGAL, L. Relações raciais no Brasil: colonialidade, dependência e diáspora. Revista Servico Social e Sociedade, São Paulo, n. 133, p. 413-431, set/ out, 2018.

ROZAS, L. B. Cotas para negros nas universidades públicas e a sua inserção na realidade jurídica brasileira - por uma nova compreensão epistemológica do princípio constitucional da igualdade. 2009. . Dissertação (Mestrado em Direito) - Faculdade de Direito, Universidade de São Paulo, São Paulo. SP, 2009.

SANTOS, S. P. dos. “Os 'intrusos' e os 'outros' no ensino superior”: relações de raça e classe nas ações afirmativas da UFES. Curitiba: Editora CRV, 2016.

UNB. Resolução $\mathbf{n}^{\circ} 38 \mathrm{CEPE}$ de 18 de junho de 2003. Aprova plano de metas para integração social, étnica e racial da universidade de Brasília. Brasília, DF, 18 de jun. 2003.

Análise do sistema de cotas para negros da universidade de Brasília. Universidade de Brasília, Brasília/DF, 2013. Disponível em: $<$ https://www.noticias.unb.br/publicacoes/67-ensino/2073-universidademais-democratica-e-inclusiva >. Acesso em: 12 dez. 2019. 